\title{
Retrospective Assessments of Childhood Psychopathology by Adults and Their Parents
}

\author{
Frederick L. Coolidge, Gina M. Tambone, Robert L. Durham, Daniel L. Segal \\ Department of Psychology, University of Colorado at Colorado Springs, Colorado Springs, USA. \\ Email: fcoolidg@uccs.edu \\ Received January $22^{\text {nd }}, 2011$; revised March $9^{\text {th }}, 2011$; accepted April 10 $0^{\text {th }}, 2011$.
}

\begin{abstract}
The present study compared retrospective personality and psychopathological assessments of adults about their childhood and adolescence with concurrent assessments by one of their parents. One-hundred three college students $\left(M_{\mathrm{age}}=23.1\right.$ years $)$ and one of their parents $\left(M_{\mathrm{age}}=51.2\right.$ years $)$ completed a retrospective version of the 200-item, parent-as-respondent, Coolidge Personality and Neuropsychological Inventory (R-CPNI). The median internal scale reliabilities (Cronbach's $\alpha$ ) for all 46 scales of the R-CPNI were substantial for the adult retrospective $(\alpha=.78)$ and the parent retrospective versions $(\alpha=.79)$, and there was a strong correlation between the adult and parent retrospective scale reliabilities $(r=.88)$. To evaluate group differences, $t$ tests revealed that the parent means were significantly lower than the adult means on 45 of the 46 scales with mostly large effect sizes. Principal components analyses of the scales for both adult and parent retrospective versions were strongly and positively correlated $(r=.88)$ for the total number of components extracted. These findings appear to support the contention that retrospective assessments tend to be reliable and valid and that parents' retrospective recollections of their children's psychopathology tend to be more positive than the retrospective reports by the adults. Based on these preliminary findings, it appears that the R-CPNI may provide a unique and interesting tool for the retrospective measurement of psychopathology.
\end{abstract}

Keywords: Coolidge Personality and Neuropsychological Inventory, R-CPNI, CPNI, Retrospective Assessment, Psychopathology

\section{Introduction}

Studies of retrospection, as a method of research beginning in the 1960 s, sought to identify factors that influenced the degree and nature of the correspondence between recollections and substantiated facts. In general, it was found that retrospective presentations were generally accurate, but frequently biased by social desirability. Specifically, mothers tended to report greater precocity in their children's developmental milestones and fewer difficulties (e.g., Yarrow, Campbell, \& Burton, 1970). In another classic study, Wetzler and Sweeney (1986) found that adults generally have no direct recall of experiences that occurred during the first five years of their lives. After the age of six, adult retrospective reports tend to become more reliable and are generally thought to be more accurate. However, substantiated details tend to be forgotten while central features of particular episodes are remembered (e.g., Sheingold $\&$ Tenney, 1982). Additionally, episodic memories are more likely to be accurate for experiences that are recent, distinctive, and unique. Ironically, it has also been found that memories are likely to be more accurate for experiences that are more frequent, typical, and regular (e.g., Belli, 1988; Brewer, 1986; Menon, 1994).

In a review of retrospective assessments of childhood psychopathology, Brewin, Andrews, and Gotlib (1993) noted that the retrospective assessment literature generally claimed that autobiographical memories had both low reliability and validity, that memory impairments were associated with specific types of psychopathology, and that the mood state during recollection biased recollections. In their review, however, Brewin et al. concluded that all three claims were exaggerated. They found that psychopathological adults did consistently report problematic behaviors in childhood and adolescence. Another consistent theme was parents' recollections of their children were more positive than the reports by the children themselves, by siblings, or by independent observers (Parker, 1981; Robbins, 1963; Schwartz, Barton-Henry, \& Pruzinsky, 1985; Yarrow et al., 1970). Brewin et al. interpreted this effect as a self-serving bias in parents that minimized their own parental mistakes and minimized problematic behaviors of their children. It is not certain, however, whether adult recollections of their own childhood psychopathological behaviors would be less positive when compared to their parents' recollections of these same behaviors. One could argue that adults would be more accurate in reporting on their own internal experiences (e.g., feelings of depression, anxiety, or anger; negative thought patterns) than would other raters of these same experiences. One could also argue that the strongest factor in a response to a self-report test item is simply the content of the item rather than social desirability and self-serving biases (e.g., Carver \& Scheier, 2008).

Henry, Moffitt, Caspi, Langley, and Silva (1994) examined 1,008 18-year-olds, both developmentally and retrospectively, from the age of 3-years-old. Reports in seven different content domains were also compared to parental and teacher reports. They found that psychosocial variables, such as subjective psychological states, produced the lowest level of agreement between developmental and retrospective measures, and they concluded that retrospective psychosocial measures should be approached with caution. However, an examination of their content domains revealed that many of the questions assessing 
the domains were either non-specific (e.g., "...did you feel depressed or anxious?" and "What was your general activity level?") or were coupled to specific age ranges (e.g., "Think about emotions when you were about 9 to 11 years old."). Not surprisingly, correlations associated with questions of this nature were all poor (e.g., $r=-.02$ to .11). However, when the questions assessed more specific behaviors (e.g., shoplifting, arrests as a juvenile, juvenile court appearances, etc.) or allowed for a more general age range (e.g., "...prior to age 17"), the correlations were deemed "moderately good" (p. 98), (i.e., $r$ $=.39$ to .48 ).

Hardt and Rutter (2004) performed a meta-analysis of 14 studies of retrospective recall and long-term reliability of retrospective recall where the samples contained at least 40 participants, and the participants were asked to report on early childhood sexual abuse, physical abuse, physical or emotional neglect, or family discord. Interestingly, they concluded that retrospective reports in adulthood of major adverse experiences in childhood involved a substantial rate of false negatives whereas false positives were probably rare. These biases, however, they purported, were not sufficient to invalidate retrospective studies of major adversities when the latter were reasonably operationalized. It may be important to note, in their conclusions, that retrospective reports "to some extent" (p. 270) produced associations with psychopathology that were biased by clinical samples. They noted that some individuals who are well-functioning in adult life might not come to the attention of clinical researchers, and that these individuals may be more likely to deny, forget, or overcome their adverse childhood histories compared to those adults who did remember them and were currently "suffering social impairment" (p. 270). In summary, a review of the latter two studies (Henry et al., 1994; Hardt \& Rutter, 2004) suggests that there are biases inherent in retrospective psychological assessment, but validity is moderately sufficient where the assessment is not bound to narrow time periods and the behaviors to be assessed are adequately specific and operationalized. In their literature review, Klonsky, Oltmanns, and Turkheimer (2002) also suggested modest agreement between self-reports and informants for personality disorders, although they did not assess retrospective reports.

The purpose of the present study was to compare retrospective personality and psychopathological assessments of adults about their childhood and adolescence (before the age of 15) with the same assessments made by one of their parents in order to investigate the psychometric reliabilities and the congruence between their ratings. If a parental bias (i.e., halo effect) is as consistent and substantial as the literature in this area suggests, then it would be important to provide additional sources of information about childhood behavior and to determine how these additional sources vary from the traditional parental assessments. Furthermore, diagnoses in clinical settings often involve reports of earlier behaviors. For example, the diagnosis of antisocial personality disorder in the Diagnostic and Statistical Manual of Mental Disorders (DSM-IV-TR; American Psychiatric Association, 2000) requires prior evidence of a conduct disorder before the age of 15 years. Therefore, validating measures which help to assess childhood behaviors, especially retrospectively, may not only contribute to research and theory in this area, but will also contribute to clinical practice. In the present study, it was hypothesized that the personality scales to be examined would be reliable (internal scale reliability as determined by Cronbach's $\alpha$ ) for retrospective reports of adults and their parents, that there would be a high positive correlation between the adult and parent scales, and that the parents' retrospective reports would generally be lower (less psychopathology). Additionally, it was hypothesized that a principal components analysis (PCA) would reveal a similar component structure (i.e., number of components extracted) and a similar amount of variance accounted for by each component, thus, ensuring a similarity in underlying component structures in adult and parents assessments.

\section{Method}

\section{Participants}

A total of 103 adult college students were recruited in their psychology classes to participate for extra credit. There were 16 men and 87 women, ages 18 to 59 years, $M_{\text {age }}=23.1$ years, primarily Caucasian (72\%), Hispanic (11\%), African American (8\%), Asian or Pacific Islander $(6 \%)$, and other $(3 \%)$. The marital status of the adult respondents at the time of participation was as follows: single ( $82 \%)$, married (14\%), and divorced (4\%). These respondents then were asked to recruit the parent most involved in their rearing. The parent respondent group consisted of 12 men and 91 women, ages 38 to 80 years, $M_{\text {age }}=$ 51.2 years, primarily Caucasian (78\%), African American (7\%), Hispanic (6\%), Asian or Pacific Islander (6\%), and other (4\%). The marital status of the parents while the child was living at home were as follows: married $(80 \%)$, divorced, single, or widowed $(18 \%)$, and other $(2 \%)$. The parents' years of education were as follows: less than a high school education $(4 \%)$, high school education (18\%), some college (30\%), and college degree or greater $(48 \%)$.

\section{Measure}

The adult respondents and their parents independently completed a retrospective version of the Coolidge Personality and Neuropsychological Inventory (CPNI; Coolidge, 1998; Coolidge, Thede, Stewart, \& Segal, 2002). The CPNI is a standardized measure of children's and adolescents' (ages 5-17 years) psychological and neuropsychological functioning. The 200-item, parent-as-respondent CPNI assesses (a) five Axis I syndromes from the $D S M-I V-T R$ (conduct disorder, oppositional defiant disorder, attention-deficit/hyperactivity disorder [ADHD], depressive disorder, and overanxious disorder of childhood), (b) nine personality disorders and their features (avoidant, borderline, dependent, histrionic, narcissistic, obsessive-compulsive, paranoid, schizoid, schizotypal) according to the criteria on Axis II of $D S M-I V-T R$ and two personality disorders in its appendix (passive-aggressive and depressive; [Note: antisocial personality disorder is not assessed by the CPNI as a personality disorder because it requires a minimum age of 18 years, however, in the present study, the Axis I conduct disorder is included as an Axis II personality disorder]), (c) three neuropsychological-behavioral syndromes including mild neurocognitive disorder (in the appendix of $D S M-I V-T R$ ), general neuropsychological dysfunction, and executive function deficits (and its three subscales: Decision-Making, Metacognitions [Language-Memory-Learning], and Social Judgment), and (d) four clinical scales, Dangerousness, Aggression, Emotional Lability, 
and Disinhibition. The CPNI also includes a 3-item scale, Antisocial Triumvirate, which assesses bed-wetting, fire-setting, and cruelty to animals. The CPNI uses a 4-point Likert-type scale ranging from 1 (strongly false) to 4 (strongly true). The CPNI normative sample consists of 780 children, ages 5 to 17 years, 30 boys and 30 girls at each age level. The 11 personality disorder scales have a median internal scale reliability of .71 and a median test-retest reliability of .81 (four to six week interval). The five Axis I scales have a median internal scale reliability of .81 and a median test-retest reliability of .87 . The three neuropsychological scales have a median internal scale reliability of .91 and a median test-retest reliability of .83 . The four clinical scales have a median internal scale reliability of .78 and a median test-retest reliability of .87 .

The general construct validity of the CPNI scales has been demonstrated in a variety of clinical and non-clinical empirical studies including children with ADHD (Coolidge, Starkey, \& Cahill, 2007), children with conduct disorders and ADHD (Coolidge, Thede, \& Young, 2000), children with executive function deficits (Coolidge, Thede, \& Jang, 2004), bullies (Coolidge, DenBoer, \& Segal, 2004), children with personality disorders and their features (Coolidge, Thede, \& Jang, 2001), children with borderline personality disorder features (Coolidge, Segal, Stewart, \& Ellett, 2000), children in the autistic spectrum (Thede \& Coolidge, 2006), children with gender identity disorder (Coolidge, Thede, \& Young, 2002), and children with chronic nightmares (Coolidge, Segal, Coolidge, Spinath, \& Gottschling, 2009).

The retrospective versions of the CPNI (R-CPNI), for self and for parents, were rewritten versions of the CPNI to assess behaviors of the adult respondents when they were children before the age of 15 . All of the questions remained the same, but the language was changed to reflect retrospection. The RCPNI contains (a) six Axis I syndromes from the DSM-IV-TR (ADHD, gender identity disorder, generalized anxiety disorder, major depressive disorder, oppositional defiant disorder, and separation anxiety disorder), (b) ten personality disorders and their features (avoidant, borderline, conduct disorder [see following note], dependent, histrionic, narcissistic, obsessivecompulsive, paranoid, schizoid, schizotypal) and two personality disorders in its appendix (passive-aggressive and depressive), (c) two neuropsychological-behavioral syndromes including mild neurocognitive disorder (in the appendix of $D S M-I V-T R$ ) and post-concussional disorder, (d) two eating disorder scales (Anorexia Nervosa and Bulimia Nervosa), (e) seven clinical scales (Emotional Coldness, Emotional Problems, Psychotic Thinking, Sleep Disturbances, Social Anxiety, Social Withdrawal, and Somatic Problems), (f) six neuropsychological dysfunction scales (Language Problems, Learning Problems, Memory Problems, Perceptual Motor Integration Problems, Subcortical Symptoms and Tics, and Maturational Delay), (g) three executive functions deficit scales (Decision-Making, Metacognitions, and Social Judgment) (h) two dangerousness scales (Antisocial Triumvirate and Dangerousness), and (i) a Denial scale. It should be noted that among the personality disorders, conduct disorder is assessed as an Axis II personality disorder in place of antisocial personality disorder because the $D S M-I V-T R$ requires that a person be 18 years of age or older to be diagnosed with antisocial personality disorder.

\section{Procedure}

Volunteer participants were given two separate packets of materials which each included the informed consent, either the self-report or parent version of the R-CPNI, and a debriefing statement. The participants were instructed to complete their forms at home, but separate from their parents. They were further instructed to inform their parents to seal their packets after completion and to return both packets to the experimenter to receive their extra credit.

\section{Results}

A summary of analyses for all scales of the R-CPNI appears in Table 1. The median internal scale reliabilities (Cronbach's $\alpha$ ) for all 46 scales of the R-CPNI were substantial for both the adult ( $\alpha=.78$, range $\alpha=.44$ to .94 ) and the parent retrospective versions ( $\alpha=.79$, range $\alpha=.24$ to .94$)$. For the personality disorders, all of the $\alpha$ 's were .63 or above with the exception of the Schizoid scale. Besides the Schizoid scale, the lowest scale reliabilities were associated with scales with the fewest items. For example, the two 3-item scales (Subcortical and Antisocial Triumvirate) had adult and parent scale reliabilities ranging from .24 to .45 . There was, however, a notable exception; the only 2-item scale (Memory Problems) yielded reliabilities of $\alpha$ $=.85$ and $\alpha=.86$ for the adult and parent retrospective versions, respectively. Overall, the adult and parent internal scale reliabilities were remarkably similar. The correlation between the 46 scale reliabilities between adults and parents was $r=.89, p$ $<.001$.

Table 1 also presents a summary of $t$ tests (and effect sizes) performed between the adult and parent means on the 46 scales. It is interesting to note that there were significant differences between the means on 45 of the 46 scales (with the exception of the Maturational Delay scale), and without exception, the adult means were higher than the parent means. With respect to effect sizes, 38 of the 46 scales yielded a large effect size, 4 yielded medium effect sizes, 3 yielded small effect sizes, and only 1 scale (Maturational Delay) did not meet the minimum for a small effect size. A summary of the correlations between the adult and parent means on the 46 scales also appears in Table 1. The median correlation between the two sets of scores for the 12 personality disorder scales was $r(10)=.44$, and the median correlation across the 46 scales was $r(44)=.47$.

Table 2 presents a summary of the PCA (PASW 17.0) for the 12 personality disorder scales of the adult and parent versions (as these are the only scales of the R-CPNI that contain every explicit criterion from the $D S M-I V-T R)$. As can be seen in Table 2 , there was a strong positive correlation $[r(12)=.88, p$ $<.001]$ between the total number of components extracted between the two versions. The percentages of variance accounted for by the components between the two versions were also positively correlated $[r(12)=.45, p=.14]$.

As noted previously, the CPNI contains a Denial scale, which assesses the tendency of a parent to deny psychopathology on 191 of the 200 CPNI items. The R-CPNI Denial scale mean $(276.60, S D=62.95)$ for the parents was significantly lower than the mean for the adults $(329.03, S D=65.79)$ with a large effect size. The normative mean on the Denial scale for the CPNI is $(306.70, S D=56.00)$.

An additional comparison was made between the adult and parent retrospective means on the 21 primary R-CPNI scales (without subtypes or subscales) and the means on these 21 scales from the normative CPNI data obtained from contempo- 
rary ratings of 780 parents of their children ages 5 to 17 years (see Table 3 for a summary of the scale mean $T$ scores). These results indicated that adults retrospectively assessing their own childhood behavior ( $M=52.71$ of the 21 scales) did not differ significantly from the ratings of the CPNI normative parents assessing their children's behavior $(M=50.00), t(20)=1.64, p$
$=.118$, although the parents' retrospective ratings of their children $(M=46.17)$ were significantly lower than the CPNI normative parents' ratings, $t(20)=-3.28, p=.004$, and the parents' retrospective ratings were also significantly lower than the adult retrospective ratings of their own childhood, $t(20)=6.89$, $p<.0005$.

Table 1.

A Summary of the Psychometrics of the R-CPNI Scales and Subscales for Adult and Parent Versions.

\begin{tabular}{|c|c|c|c|c|c|c|c|c|c|c|c|c|c|c|}
\hline & \multirow[b]{2}{*}{$\begin{array}{c}\text { Items in } \\
\text { Scale }\end{array}$} & \multicolumn{3}{|c|}{$\begin{array}{l}\text { Adult Retrospective } \\
\text { Version }\end{array}$} & \multicolumn{3}{|c|}{$\begin{array}{c}\text { Parent Retrospective } \\
\text { Version }\end{array}$} & \multirow[b]{2}{*}{$N$} & \multirow[b]{2}{*}{$r$} & \multirow[b]{2}{*}{$p$} & \multirow[b]{2}{*}{$N$} & \multirow[b]{2}{*}{$t$} & \multirow[b]{2}{*}{$p$} & \multirow[b]{2}{*}{$r^{*}$} \\
\hline & & $M$ & $S D$ & $\begin{array}{l}\text { Std* } \\
\text { Alpha }\end{array}$ & $M$ & $S D$ & $\begin{array}{c}\text { Std } \\
\text { Alpha }\end{array}$ & & & & & & & \\
\hline \multicolumn{15}{|l|}{$D S M-I V-T R$ Axis I Scales (including subtypes) } \\
\hline Attention-Deficit/Hyperactivity Disorder (ADHD) & 18 & 30.97 & 8.57 & .88 & 25.98 & 8.18 & .90 & 103 & .45 & $<.001$ & 103 & 5.89 & $<.001$ & .50 \\
\hline ADHD Inattention Type & 9 & 15.84 & 5.40 & .87 & 13.51 & 5.21 & .89 & 103 & .47 & $<.001$ & 103 & 4.43 & $<.001$ & .40 \\
\hline ADHD Hyperactivity-Impulsivity Type & 9 & 15.13 & 4.27 & .75 & 12.47 & 3.87 & .78 & 103 & .38 & $<.001$ & 103 & 5.99 & $<.001$ & .51 \\
\hline Gender Identity Disorder & 6 & 9.15 & 3.46 & .84 & 7.36 & 2.46 & .87 & 103 & .48 & $<.001$ & 103 & 5.57 & $<.001$ & .48 \\
\hline Generalized Anxiety Disorder & 12 & 24.21 & 6.52 & .83 & 19.73 & 6.59 & .86 & 103 & .54 & $<.001$ & 103 & 7.14 & $<.001$ & .58 \\
\hline Major Depressive Disorder & 15 & 28.37 & 8.26 & .87 & 23.47 & 7.04 & .87 & 103 & .51 & $<.001$ & 103 & 6.57 & $<.001$ & .55 \\
\hline Oppositional Defiant Disorder & 8 & 13.98 & 4.26 & .80 & 12.13 & 4.11 & .83 & 103 & .46 & $<.001$ & 103 & 4.46 & $<.001$ & .40 \\
\hline Separation Anxiety Disorder & 8 & $\begin{array}{c}13.34 \\
\text { Median }\end{array}$ & 4.51 & $\begin{array}{l}.84 \\
.84\end{array}$ & 11.38 & 3.88 & $\begin{array}{l}.82 \\
.87\end{array}$ & 103 & $\begin{array}{l}.46 \\
.47\end{array}$ & .00 & 103 & 4.47 & $<.001$ & .40 \\
\hline \multicolumn{15}{|l|}{ Personality Disorder Scales (including subtypes) } \\
\hline Avoidant & 7 & 15.36 & 5.04 & .88 & 12.47 & 4.60 & .85 & 103 & .49 & $<.001$ & 103 & 6.01 & $<.001$ & .51 \\
\hline Borderline & 9 & 17.22 & 4.71 & .74 & 14.25 & 4.21 & .77 & 103 & .44 & $<.001$ & 103 & 6.34 & $<.001$ & .53 \\
\hline Conduct Disorder & 15 & 19.05 & 4.66 & .80 & 16.61 & 3.19 & .80 & 103 & .44 & $<.001$ & 103 & 5.72 & $<.001$ & .49 \\
\hline Conduct Disorder - Aggressive & 7 & 8.37 & 2.09 & .66 & 7.63 & 1.55 & .58 & 103 & .48 & $<.001$ & 103 & 3.91 & $<.001$ & .36 \\
\hline Conduct Disorder - Delinquent & 8 & 10.68 & 3.31 & .74 & 8.98 & 2.00 & .70 & 103 & .37 & $<.001$ & 103 & 5.44 & $<.001$ & .47 \\
\hline Dependent & 8 & 15.23 & 3.63 & .63 & 12.74 & 3.71 & .72 & 103 & .37 & $<.001$ & 103 & 6.17 & $<.001$ & .52 \\
\hline Depressive & 7 & 15.84 & 4.82 & .84 & 12.99 & 4.22 & .82 & 103 & .56 & $<.001$ & 103 & 6.75 & $<.001$ & .56 \\
\hline Histrionic & 8 & 15.09 & 3.67 & .66 & 12.98 & 3.97 & .79 & 103 & .46 & $<.001$ & 103 & 5.38 & $<.001$ & .47 \\
\hline Narcissistic & 9 & 15.78 & 3.95 & .75 & 12.36 & 3.55 & .79 & 103 & .40 & $<.001$ & 103 & 8.41 & $<.001$ & .64 \\
\hline Obsessive-Compulsive & 8 & 16.56 & 4.15 & .67 & 13.77 & 4.09 & .73 & 103 & .46 & $<.001$ & 103 & 6.64 & $<.001$ & .55 \\
\hline Paranoid & 7 & 14.27 & 4.11 & .76 & 11.29 & 3.64 & .79 & 103 & .40 & $<.001$ & 103 & 7.10 & $<.001$ & .58 \\
\hline Passive-Aggressive & 7 & 12.69 & 3.66 & .75 & 10.92 & 3.27 & .74 & 103 & .33 & $=.001$ & 103 & 4.47 & $<.001$ & .40 \\
\hline Schizoid & 7 & 12.15 & 2.84 & .47 & 11.44 & 3.17 & .50 & 103 & .43 & $<.001$ & 103 & 2.23 & 0.03 & .22 \\
\hline Schizotypal & 10 & 16.12 & 4.78 & .78 & 13.03 & 3.17 & .73 & 103 & .38 & $<.001$ & 103 & 6.78 & $<.001$ & .56 \\
\hline & & Median & & .75 & & & .76 & & .44 & & & & & \\
\hline \multicolumn{15}{|l|}{$D S M-I V$-TR Appendix Scales } \\
\hline Mild Neurocognitive Disorder & 16 & 24.87 & 7.66 & .90 & 21.76 & 7.06 & .90 & 103 & .57 & $<.001$ & 103 & 4.72 & $<.001$ & .42 \\
\hline Postconcussional Disorder & 17 & 34.72 & 9.68 & .89 & 28.64 & 9.05 & .90 & 103 & .51 & $<.001$ & 103 & 6.64 & $<.001$ & .55 \\
\hline & & Median & & .90 & & & .90 & & .54 & & & & & \\
\hline \multicolumn{15}{|l|}{ Eating Disorder Scales } \\
\hline Anorexia Nervosa & 4 & 7.19 & 2.78 & .63 & 6.14 & 2.58 & .69 & 103 & .62 & $<.001$ & 103 & 4.46 & $<.001$ & .40 \\
\hline Bulimia Nervosa & 6 & 8.89 & 3.50 & .80 & 7.79 & 3.07 & .79 & 103 & .48 & $<.001$ & 103 & 3.29 & $=.001$ & .31 \\
\hline & & Median & & .72 & & & .74 & & .57 & & & & & \\
\hline \multicolumn{15}{|l|}{ Clinical Scales } \\
\hline Emotional Coldness & 4 & 5.95 & 1.83 & .54 & 5.57 & 1.92 & .71 & 103 & .52 & $<.001$ & 103 & 2.14 & .03 & .21 \\
\hline Emotional Problems & 10 & 21.26 & 6.23 & .86 & 17.72 & 5.82 & .87 & 103 & .55 & $<.001$ & 103 & 6.27 & $<.001$ & .53 \\
\hline Psychotic Thinking & 9 & 14.91 & 4.71 & .80 & 11.57 & 3.07 & .76 & 103 & .40 & $<.001$ & 103 & 7.60 & $<.001$ & .60 \\
\hline Sleep Disturbances & 7 & 11.61 & 3.56 & .60 & 9.63 & 3.27 & .72 & 103 & .39 & $<.001$ & 103 & 5.35 & $<.001$ & .47 \\
\hline Social Anxiety & 11 & 23.02 & 6.99 & .88 & 18.45 & 6.28 & .88 & 103 & .51 & $<.001$ & 103 & 7.11 & $<.001$ & .58 \\
\hline Social Withdrawal & 11 & 21.61 & 6.28 & .86 & 17.74 & 5.58 & .85 & 103 & .51 & $<.001$ & 103 & 6.74 & $<.001$ & .56 \\
\hline Somatic Problems & 6 & 10.08 & 3.23 & .66 & 8.34 & 2.50 & .57 & 103 & .36 & $<.001$ & 103 & 5.26 & $<.001$ & .46 \\
\hline & & Median & & .80 & & & .76 & & .51 & & & & & \\
\hline Neuropsychological Dysfunction Scales & & & & & & & & & & & & & & \\
\hline chological Dysfunction & 38 & 58.29 & 15.34 & .93 & 50.70 & 13.67 & .92 & 103 & .54 & $<.001$ & 103 & 5.67 & $<.001$ & .49 \\
\hline Language Problems & 5 & 6.94 & 2.40 & .70 & 5.86 & 1.84 & .67 & 103 & .42 & $<.001$ & 103 & 4.73 & $<.001$ & .42 \\
\hline Learning Problems & 4 & 6.18 & 2.37 & .76 & 5.48 & 2.03 & .77 & 103 & .63 & $<.001$ & 103 & 3.90 & $<.001$ & .36 \\
\hline Memory Problems & 2 & 3.57 & 1.63 & .85 & 2.93 & 1.33 & .86 & 103 & .42 & $<.001$ & 103 & 3.94 & $<.001$ & .36 \\
\hline Perceptual Motor Integration Problems & 4 & 5.35 & 1.86 & .67 & 4.75 & 1.38 & .40 & 103 & .43 & $<.001$ & 103 & 3.62 & $<.001$ & .34 \\
\hline Subcortical Symptoms and Tics & 3 & 4.19 & 1.44 & .45 & 3.59 & 1.14 & .24 & 103 & .36 & $<.001$ & 103 & 4.29 & $<.001$ & .39 \\
\hline Maturational Delay & 5 & 5.83 & 1.41 & .51 & 5.78 & 1.48 & .51 & 103 & .56 & $<.001$ & 103 & .29 & .77 & .03 \\
\hline & & Median & & .70 & & & .67 & & .43 & & & & & \\
\hline
\end{tabular}




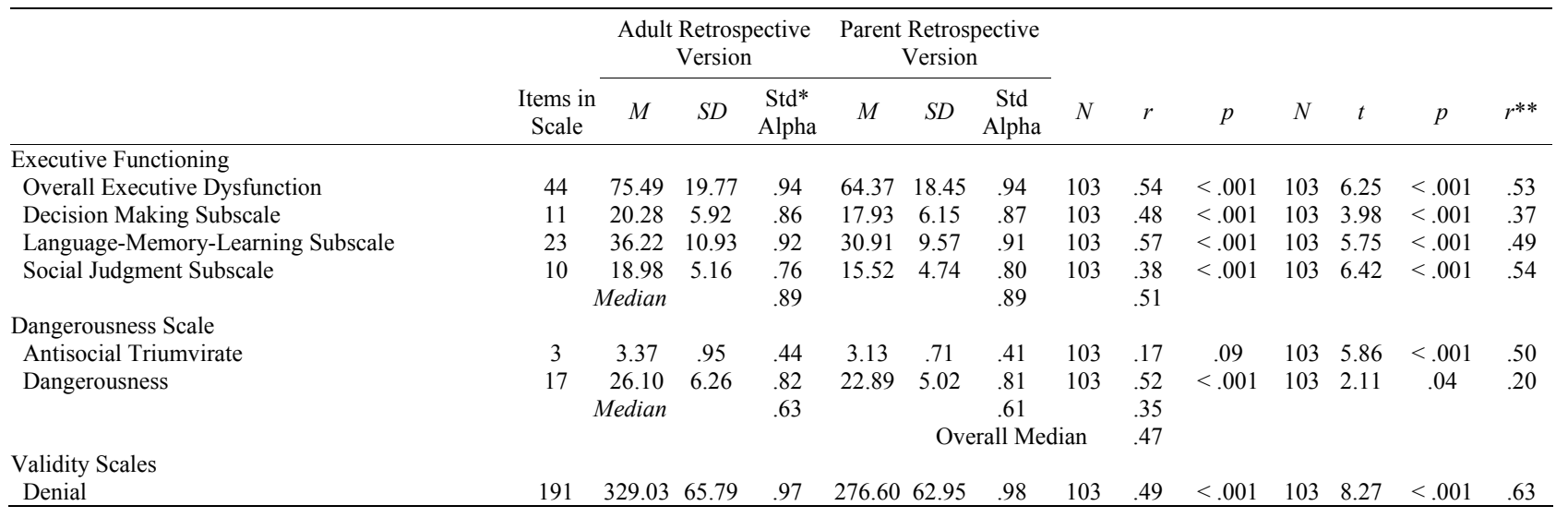

* Standardized; $* * r$ represents the correlation of effect size; minimum value for small $=.10$, medium $=.24$, large $=.37$.

Table 2 .

A Summary of the Principal Components Analyses for the R-CPNI between Adult and Parent Versions for the 12 Personality Disorder Scales.

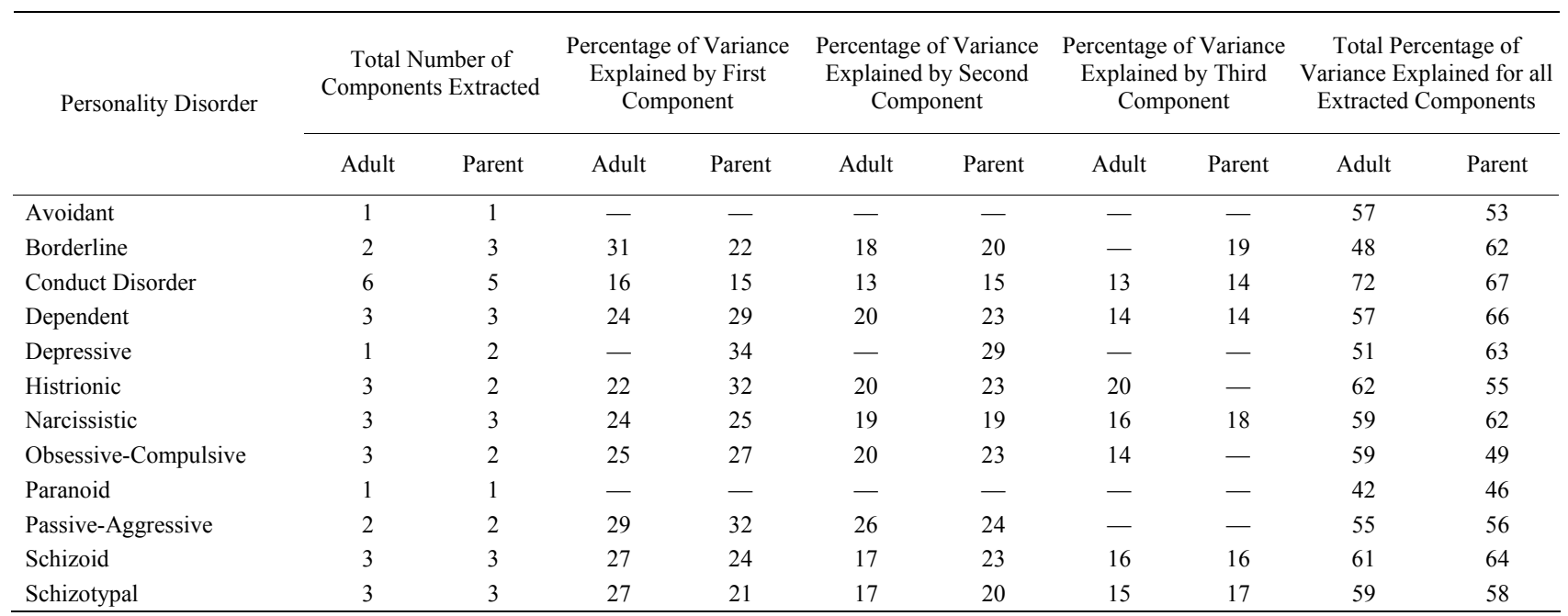

\section{Discussion}

The present findings appear to confirm the primary hypothesis that personality disorder features, clinical disorders, and neuropsychological scales of a retrospective version of the CPNI would be internally reliable for both adult and parent versions. As noted previously, the median reliability coefficients for the adult and parent retrospective versions were $\alpha$ $=.78$ and $\alpha=.79$, respectively, across all 46 scales and subscales. Interestingly, and also as hypothesized, the parents' scale means were significantly lower than the adult retrospective means with only one exception, and most differences had large effect sizes (38 of 46 scales). In many respects, the latter finding is consistent with the early literature that suggested parents viewed their children's behaviors more favorably in retrospect. As noted earlier, Brewin et al. (1993) proposed that this effect may have been a self-serving bias in parents that minimized their parental mistakes, perhaps leading them to feel less guilty or inadequate as parents. Whether this process is intentional or out of conscious awareness is a topic for further study.
There was also evidence that the retrospective assessments of the adults were not significantly different from those by parents who were contemporarily rating their children's behavior. Furthermore, there was additional evidence that the parents' retrospective ratings of their children produced some "halo effect," as their ratings were shown to be significantly lower than parents who were contemporarily rating their children's behavior. Nevertheless, we might argue that given the great similarities between the underlying component structures between the parent and adult retrospective scales, the parents' retrospective evaluations possess sufficient construct validity for valid psychopathological assessment. Evidence for the general similarity between the ratings also comes from the moderate to strong correlations between adults and parents retrospective mean ratings. For example, the median correlation for the 12 personality disorder scales between the two sets of scores of $r=.44$ is similar to research of married people's self and spouses ratings of 13 personality disorders, which found a median correlation of $r=.46$ (Coolidge, Burns, \& Mooney, 1995). It may also important to note a recent study (Leising, Erbs, \& Fritz, 2010) found that the halo effect may not be unique to parental reports 
or child-parent dyads. Leising et al. determined that informants who "liked" the targets described them more positively, while informants who simply had knowledge of the targets described them with somewhat better accuracy.

There are a number of issues for interpreting the present data. One major issue appears to be whether adult retrospective assessments might have a tendency to over-pathologize their childhood behavior. It does seem clear, however, that parents' retrospective evaluations of their children's behavior have a tendency to under-pathologize, although the adult retrospective and parent retrospective evaluations remain well within a standard deviation of parents rating the current psychopathology of their children. Certainly adjunct contemporary behavioral assessments would be important in assessing whether parents have a tendency to under-pathologize their children's current behavior. Longitudinal studies are needed to more explicitly address these issues.

In summary, the present findings support the earlier claims of Brewin et al. (1993) that retrospective assessments tend to be reliable and valid and that parents' recollections of their adult children's psychopathology tends to be more positive than retrospective reports by the adults. The present study also reinforces recent claims by Leising et al. (2010), as noted earlier, that informants who were fond of the people they were describing described them more positively, regardless of whether they were the parents of the targets. The present findings are also consistent with the meta-analysis by Hardt and Rutter (2004) of the reliability and validity of retrospective recall, where they found sufficient evidence for the general validity of retrospective evaluations. Two of their findings and those by Henry et al. (1994) bear further attention. First, future studies may wish to address the potential artifact that those who do not deny, forget, or overcome their adverse childhood histories are more likely to remember them than adults without adverse histories. Second, consistent with the findings of Hardt and Rutter and Henry et al., it may be that retrospective assessment may increase in reliability and validity where broader time periods are evaluated and the assessed behaviors are clearly specified and operationalized.

The present study is limited by choosing a sample of convenience: mostly young women Caucasian college students with a psychology major. It might be expected that such as sample would result in a restricted range of psychopathology, but an examination of the data (i.e., Table 3) revealed sufficient levels of psychopathology for particular disorders and sufficient variation across disorders. There is also the possibility that some of the parents, although they sealed their packets after completing the inventory, and they were all instructed to complete the inventories independently, some may have skewed their reports knowing the adult was responsible for returning both sealed packets to the experimenter. Future studies may wish to correct for this potential confounding by having the parents return the packets directly to the experimenter and including a validity check. It might also be useful if future studies were conducted upon a variety of clinical samples, such as adults with ADHD, or if future studies examined whether agreement from the sources varied in other personality domains besides psychopathology, e.g., extraversion-introversion, warmth, boldness, affiliation, etc. Additionally, because of the likelihood that parents are not necessarily equal in their abilities to rate their children, future research might include both parents as
Table 3.

Mean T scores for 21 Primary R-CPNI Scales.

\begin{tabular}{lcc}
\hline \multicolumn{1}{c}{ Scale } & Adult & Parent \\
\hline Attention-Deficit/Hyperactivity Disorder & 46.40 & 41.31 \\
Avoidant Personality Disorder (PD) & 59.60 & 51.34 \\
Borderline PD & 52.76 & 44.73 \\
Conduct Disorder & 49.48 & 44.40 \\
Dependent PD & 53.51 & 46.40 \\
Depressive PD & 57.54 & 49.40 \\
Executive Functioning & 48.99 & 43.14 \\
Generalized Anxiety Disorder & 58.62 & 49.66 \\
Gender Identity Disorder & 57.61 & 49.83 \\
Histrionic PD & 53.03 & 47.17 \\
Major Depressive Disorder & 52.30 & 45.94 \\
Mild Neurocognitive Disorder & 47.75 & 43.71 \\
Narcissistic PD & 51.35 & 43.40 \\
Neuropsychological Dysfunction & 47.98 & 43.05 \\
Obsessive-Compulsive PD & 53.82 & 45.36 \\
Oppositional Defiant Disorder & 47.07 & 42.96 \\
Paranoid PD & 56.68 & 47.06 \\
Passive-Aggressive PD & 49.69 & 44.63 \\
Separation Anxiety Disorder & 54.21 & 49.18 \\
Schizotypal PD & 57.20 & 48.37 \\
Schizoid PD & 51.35 & 48.62 \\
Mean & 52.71 & 46.17 \\
\hline
\end{tabular}

* The mean T score of the CPNI normative sample for all scales is $50(S D=10)$.

raters and also assess the time of parental contact raising their children. Despite these limitations and an apparent tendency of parents to view their children retrospectively in a more positive light, it appears, based on these preliminary findings, the R-CPNI may provide an interesting tool for the retrospective measurement of psychopathology.

\section{References}

American Psychiatric Association. (2000). Diagnostic and statistical manual of mental disorders (4th ed., text revision). Washington, DC: Author.

Belli, R. F. (1988). Color blend retrievals: Compromise memories or deliberate compromise responses? Memory and Cognition, 16, 314-326. doi:10.3758/BF03197042

Brewer, W. F. (1986). What is autobiographical memory? In D. C. Rubin (Ed.), Autobiographical memory (pp. 25-49). New York, NY: Cambridge University Press. doi:10.1017/CBO9780511558313.006

Brewin, C. R., Andrews, B., \& Gotlib, I. H. (1993). Psychopathology and early experience: A reappraisal of retrospective reports. Psychological Bulletin, 113, 82-98. doi:10.1037/0033-2909.113.1.82

Carver, C. S., \& Scheier, M. F. (2008). Perspectives on personality (6th ed.). Upper Saddle River, NJ: Pearson.

Coolidge, F. L. (1998). Coolidge personality and neuropsychological inventory for children manual: CPNI. Colorado Springs, CO: Author.

Coolidge, F. L., DenBoer, J. W., \& Segal, D. L. (2004). Personality and neuropsychological correlates of bullying behavior. Personality and Individual Differences, 36, 1559-1569.

doi:10.1016/j.paid.2003.06.005

Coolidge, F. L., Segal, D., Stewart, S., \& Ellett, J. (2000). Neuropsychological dysfunction in children with borderline personality disor- 
der features: A preliminary investigation. Journal of Research in Personality, 34, 554-561. doi:10.1006/jrpe.2000.2298

Coolidge, F. L., Segal, D. L., Coolidge, C. M., Spinath, F. M., \& Gottschling, J. (2009). Do nightmares and generalized anxiety disorder in children and adolescence have a common genetic disorder? Behavior Genetics, 40, 249-356. doi:10.1007/s10519-009-9310-z

Coolidge, F. L., Starkey, M. T., \& Cahill, B. S. (2007). Comparison of a parent-rated $D S M-I V-T R-I V$ measure of attention-deficit/hyperactivity disorder and quantitative EEG parameters in an outpatient sample of children. Journal of Clinical Neurophysiology, 24, 348-351. doi: 10.1097/WNP.0b013e318067bcfc

Coolidge, F. L., Thede, L. L., \& Jang, K. L. (2001). Heritability of personality disorders in childhood: A preliminary investigation. Journal of Personality Disorders, 15, 33-40. doi:10.1521/pedi.15.1.33.18645

Coolidge, F. L., Thede, L. L., \& Jang, K. L. (2004). Are personality disorders psychological manifestations of executive function deficits? Bivariate heritability evidence from a twin study. Behavior Genetics, 24, 75-84. doi:10.1023/B:BEGE.0000009486.97375.53

Coolidge, F. L., Thede, L., Stewart, S., \& Segal, D. (2002). The Coolidge Personality and Neuropsychological Inventory for Children (CPNI): Preliminary psychometric characteristics. Behavior Modification, 26, 550-566. doi:10.1177/0145445502026004007

Coolidge, F. L., Thede, L. L., \& Young, S. (2000). Heritability and the comorbidity of attention deficit hyperactivity disorder with behavioral disorders and executive function deficits: A preliminary investigation. Developmental Neuropsychology, 17, 273-287. doi:10.1207/S15326942DN1703

Coolidge, F. L., Thede, L., \& Young, S. (2002). The heritability of gender identity disorder in a child and adolescent twin sample. Behavior Genetics, 32, 251-257. doi:10.1023/A:1019724712983

Hardt, J., \& Rutter, M. (2004). Validity of adult retrospective reports of adverse childhood experiences: Review of the evidence. Journal of Child Psychology and Psychiatry, 45, 260-273. doi:10.1111/j.1469-7610.2004.00218.x

Henry, B., Moffitt, T. E., Caspi, A., Langley, J., \& Silva, P. A. (1994). On the "remembrance of things past": A longitudinal evaluation of the retrospective method. Psychological Assessment, 6, 92-101. doi:10.1037/1040-3590.6.2.92

Klonsky, E. D., Oltmanns, T. F., \& Turkheimer, E. (2002). Informant reports of personality disorder: Relation to self-reports, and future research directions. Clinical Psychology: Science \& Practice, 9, 300-311. doi:10.1093/clipsy.9.3.300

Leising, D., Erbs, J., \& Fritz, U. (2010). The letter of recommendation effect in informant ratings of personality. Journal of Personality and Social Psychology, 98, 668-682. doi:10.1037/a0018771

Menon, A. (1994). Judgments of behavioral frequencies: Memory search and retrieval strategies. In N. Schwartz \& S. Sudman (Eds.), Autobiographical memory and the validity of retrospective reports (pp. 107-120). New York, NY: Springer-Verlag.

Parker, G. (1981). Parental reports of depressives: An investigation of several explanations. Journal of Affective Disorders, 3, 131-140. doi:10.1016/0165-0327(81)90038-0

Robbins, L. C. (1963). The accuracy of parental recall of aspects of child development and child rearing practices. Journal of Abnormal and Social Psychology, 66, 261-270. doi:10.1037/h0049084

Sheingold, K., \& Tenney, Y. J. (1982). Memory for a salient childhood event. In U. Neisser (Ed.), Memory observed (pp. 201-212). San Francisco, CA: Freeman.

Schwartz, J. C., Barton-Henry, M. L., \& Pruzinsky, T. (1985). Assessing child-rearing behaviors: A comparison of ratings made by mother, father, child, and sibling on the CRPBI. Child Development, 56, 462-479. doi: $10.2307 / 1129734$

Thede, L. L., \& Coolidge, F. L. (2006). Psychological and neurobehavioral comparisons of children with Asperger's disorder versus high-functioning Autism. Journal of Autism and Developmental Disorders, 37, 847-854.doi:10.1007/s10803-006-0212-0

Wetzler, S. E., \& Sweeney, J. A. (1986). Childhood amnesia: An empirical demonstration. In D. C. Rubin (Ed.), Autobiographical memory (pp. 191-201). New York, NY: Cambridge University Press. doi:10.1017/CBO9780511558313.017

Yarrow, M. R., Campbell, J. D., \& Burton, R. V. (1970). Recollections of childhood: A study of the retrospective method. Monographs of the Society for Research in Child Development, 35, 1-74. doi: $10.2307 / 1165649$ 